\title{
Role of ultrasound in diagnosis and differentiation of benign and malignant ovarian mass: A Hospital based study in Western Nepal
}

\author{
Subash KC' ${ }^{1}$, Ashish Shrestha², Sagar Khadka², Ramesh Poudel ${ }^{2}$ \\ ${ }^{1}$ Lecturer, Department of Radiodiagnosis and Imaging, Manipal Teaching Hospital, Phulbari-11, Pokhara, Nepal, \\ ${ }^{2}$ Resident doctor, Department of Radiodiagnosis and Imaging, Manipal Teaching Hospital, Phulbari-11, Pokhara, Nepal
}

\section{A B S T R A C T}

Background: As ovarian malignancies are one of the commonest malignancies in female population, timely and accurate diagnosis helps in early treatment resulting in better survival. Ultrasound is easily available diagnostic tool not only to diagnose but also accurately distinguish malignant from benign ovarian masses. Aims and Objectives: To evaluate sensitivity, specificity and accuracy of ultrasound in diagnosing and differentiating benign from malignant ovarian masses in comparison with histopathological findings. Materials and Methods: A prospective study was carried out from August 2015 to August 2018 for a period of 3 years. Total 150 patients with ovarian masses who were operated in our hospital and their final histopathological reports were available, were included in our study. Ultrasound diagnosis and histopathological diagnosis were compared. Results: Sensitivity, specificity and accuracy of ultrasound in diagnosing and differentiating malignant from benign ovarian masses were found to be $78.94 \%, 98.47 \%$ and $88.23 \%$ respectively compared with histopathological findings. Conclusion: Ultrasound is very sensitive, specific and accurate in not only diagnosing ovarian mass but also in differentiating malignant from benign entities making it invaluable and important diagnostic tool in evaluation of ovarian masses.

Key words: Ultrasound; Ovarian mass; Histopathology

\section{INTRODUCTION}

Pelvic ultrasound remains the most widely used imaging modality to assess adenexal masses. ${ }^{1,2}$ Ovarian tumours represent almost $2 / 3^{\text {rd }}$ of adenexal masses. ${ }^{3}$ Sonographic evaluation is mainly aimed to differentiate benign from malignant masses. Almost $90 \%$ of adenexal masses can be characterized only using ultrasound features of the lesion. ${ }^{4}$ Proper evaluation of adenexal mass is important because surgical intervention if possible can be applied in time, thus decreasing morbidity and mortality of patients. Ultrasound findings combined with clinical findings, other tumour markers, CT, MRI can be used to determine if patient can be kept on follow up, advised surgery or refer to gynaecological oncologist if the mass is unresectable or in advanced stage. Benign ovarian lesions are mostly cystic, unilocular and freely mobile with thin wall and septae if present are thin. No ascites is present. On the other hand, malignant ovarian lesion may be bilateral or unilateral, firm to hard in consistency, have thick wall, irregular margin, thick septations. There are solid components within the cystic lesions or papillary projections form the wall. Age specific incidence rate of ovarian cancer increases from 35 years onwards with a peak between 55 to 64 years. ${ }^{5}$ Hence, aim of our study was to know the sensitivity, specificity and accuracy of ultrasound in diagnosing as well as differentiating benign from malignant ovarian masses compared to histopathological results. 


\section{MATERIALS AND METHODS}

The current study is a prospective observational study done from Aug. 2015 to August 2018. Total number of 150 patients who attended gyanecology department of Manipal Teaching Hospital and sent to department of Radiology and Imaging whose ultrasound depicted ovarian mass and who underwent operation and histopathological report were available were included in the study. Some patients who came for USG from department other than gyanecology and in whom ovarian mass were found were then referred to gyanecology department for treatment and follow up. Such patients were also included in our study. Presenting complaints of patient, age, parity, menstrual history etc. were duly noted in our proforma other after taking informed written consent from them. Various tumor markers if sent from gyanecology department were also noted. CT or MRI done in such cases were noted and finally histopathological reports were obtained from the department of pathology of our hospital. Statistical analysis was done using SPSS (Version 16). Sensitivity, specificity and accuracy in diagnosing and differentiating benign from malignant ovarian masses were calculated based on final histopathological report.

\section{RESULTS}

In our study, patients presented with various complaints. Most of them presented with lower abdominal pain (61.6\%). Some preserved with excessive PV bleeding (14\%), irregular menstruation (13\%) some had no complaints with incidental detection of ovarian lesions during routine scan. (Figure 1).

The age of patients in our study ranged from 14 to 77 years with a mean age of 40 years. $70 \%$ of women

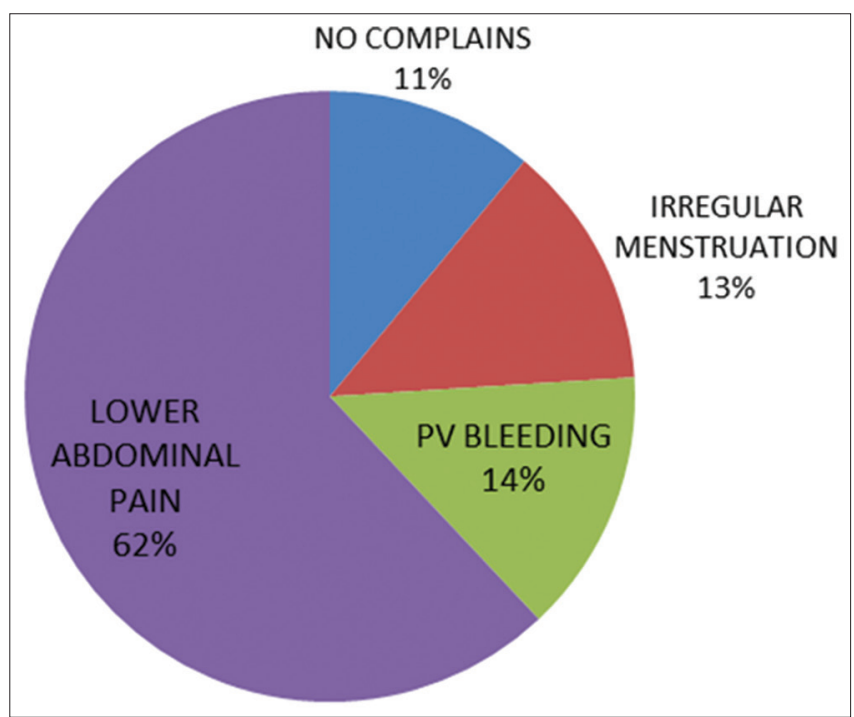

Figure 1: Presenting complains of patients with ovarian mass were in reproductive age group followed by $16.27 \%$ in postmenopausal age group. (Table 1).

When both cystic and solid components were present, most of the lesions were malignant. Solid masses were also malignant and chances of malignancy increased if cystic areas were present within the mass. If the lesion was totally solid, those showing hyperechoic appearance corresponding to fat, they were benign mostly dermoids. Almost all the cases with papillary projections were malignant. (Table 2).

When USG diagnosis were correlated with histopathological findings, 4 cases were false negative and 2 cases were false positive. Sensitivity, specificity and accuracy of ultrasound in diagnosing and differentiating malignant from benign ovarian masses were found to be $78.94 \%, 98.47 \%$ and $88.23 \%$ respectively compared with histopathological findings. (Table 3).

Most common benign ovarian lesion was dermoid (40 out of 133), followed by serous cystadenoma (25 out of 133) with other common finding being mucinous cystadenoma (12 out of 133), endometrioma (13 out of 133) and

\begin{tabular}{|c|c|c|}
\hline Age group (yrs) & Number of patients & Percentage \\
\hline $10-20$ & 8 & $5.23 \%$ \\
\hline $21-30$ & 33 & $22.09 \%$ \\
\hline $31-40$ & 33 & $22.60 \%$ \\
\hline $41-50$ & 33 & $22.09 \%$ \\
\hline $51-60$ & 19 & $12.79 \%$ \\
\hline $61-70$ & 14 & $9.30 \%$ \\
\hline $71-80$ & 10 & $6.97 \%$ \\
\hline Total & 150 & $100 \%$ \\
\hline
\end{tabular}

\begin{tabular}{lcc}
\multicolumn{3}{l}{ Table 2: USG features of ovarian masses } \\
\hline USG findings & Benign per/133 & Malignant per/17 \\
\hline Cystic & 100 & 2 \\
Solid -cystic & 11 & 12 \\
Solid & 22 & 3 \\
$\begin{array}{l}\text { Papillary } \\
\text { projection present }\end{array}$ & 2 & 17 \\
$\begin{array}{l}\text { Papillary } \\
\text { projection absent }\end{array}$ & 131 & 0 \\
\hline
\end{tabular}

\begin{tabular}{lccc} 
Table 3: Ultrasound diagnosis vs. \\
Histopathological findings \\
\hline $\begin{array}{l}\text { Ultrasound } \\
\text { diagnosis }\end{array}$ & \multicolumn{3}{c}{ Histopathological findings } \\
\cline { 2 - 4 } & $\begin{array}{c}\text { Malignany } \\
\text { present }\end{array}$ & $\begin{array}{c}\text { Malignancy } \\
\text { absent }\end{array}$ & Total \\
\hline Malignany present & 15 & 2 & 17 \\
Malignancy absent & 4 & 129 & 133 \\
Total & 19 & 131 & 150 \\
\hline
\end{tabular}




\begin{tabular}{lc} 
Table 4: Histopathological findings & \\
\hline Benign lesions & \\
\hline Dermoid & 40 \\
Serous Cystadenoma & 25 \\
Mucinous Cystadenoma & 12 \\
Endometrioma & 13 \\
Fibroma & 2 \\
Dysgerminoma & 1 \\
Fibrothecoma & 1 \\
Hemorrhagic cyst & 5 \\
Simple cyst & 10 \\
Corpus leuteal cyst & 5 \\
Struma ovarii & 2 \\
Benign brenner's tumor & 1 \\
Benign papillary serous cystadenoma & 7 \\
Endosalphingosis & 1 \\
Serous cyst adenofibroma & 2 \\
Normal/follicular cyst & 4 \\
Total & 131 \\
\hline Malignant lesions & \\
\hline Mucinous cystadenoma & 6 \\
Serous cystadenocarcinoma & 3 \\
Papillary serous cyastadenoma & 5 \\
Metastatic & 3 \\
Adenosquamous carcinoma arising in Dermoid & 1 \\
Large keratising squmaous carcinoma & 1 \\
Total & 19 \\
\hline &
\end{tabular}

hemorrhagic cysts (5 out of 133). Most common malignant ovarian lesion was mucinous cystadenocarcinoma (6 out of 17 malignant cases) followed by papillary serous cystadenocarcinoma (5 out of 17 cases) and serous cystadenocarcinoma (3 out of 17 cases). (Table 4).

\section{DISCUSSION}

Ovarian cancer are one of the malignancies with worst prognosis because there is lack of effective screening for early detection. ${ }^{6}$ Their hidden anatomical location deep in pelvis, size, shape and histological change over a woman's lifetime make it difficult to assess and detect ovarian cancer in early stages. ${ }^{7}$

Among the ovarian masses detected by ultrasound in our study, $88 \%$ were benign and $12 \%$ were malignant, which are comparable with studies done by Priya MHF et $\mathrm{al}^{8}$, Shraddha et $\mathrm{al}^{9}$ and Jha and Karki et al. ${ }^{10}$

Mean age of ovarian malignancy was 46 years in our study which is comparable to study fone by Priya MHF et $\mathrm{al}^{8}$, Wasim et $\mathrm{al}^{11}$ and Mondal et al. ${ }^{12}$ Higher incidence of ovarian cancer were found in postmenopausal age group which is comparable to other studies. ${ }^{6,11}$ On the other hand, benign ovarian lesions were more common in young and reproductive age group. Most of the patients were symptomatic where as some had incidental detection of ovarian lesion on routine scan without having any symptoms. Other studies showed finding of 7-15\% ovarian cancer patient being asymptomatic. ${ }^{6,11}$ Ultrasonography is sensitive in detecting as well as distinguishing between benign and malignant ovarian mass. Our study showed a sensitivity of $78.94 \%$, specificity of $98.47 \%$ and accuracy of $88.23 \%$ which is similar to studies done by Topez et $\mathrm{al}^{13}$, Wasim et $\mathrm{al}^{11}$, Pourissa et $\mathrm{al}^{14}$, Priya MHF et al ${ }^{8}$ and Padmawati et al. ${ }^{15}$

Among histopathological subtypes, most common ovarian malignancy was mucinous cystadenocarcinoma followed by serous cystadenocarcinoma which is similar to other studies. ${ }^{16,17}$ Similarly, among the benign lesions, dermoid was most common followed by serous as well as mucinous cystadenoma, endometrioma etc. which is comparable to study done by Radhamani et al. ${ }^{15}$

\section{CONCLUSION}

Ultrasonography is initial, easily available diagnostic modality for localizing and characterizing any ovarian mass and thus very sensitive, specific and accurate at diagnosing and distinguishing benign and malignant entities. This makes further evaluation and timely management possible.

\section{REFERENCES}

1. Atri M, Alabousi A, Reinhold C, Akin EA, Benson CB, Bhosale PR, et al. ACR Appropriateness Criteria ${ }^{\circledR}$ Clinically Suspected Adnexal Mass, No Acute Symptoms. Journal of the American College of Radiology 2019; 16(5):S77-S93.

2. Liu J, Xu Y and Wang J. Ultrasonography, computed tomography and magnetic resonance imaging for diagnosis of ovarian carcinoma. European journal of radiology 2007; 62(3):328-334.

3. Hassan AY, Ellatif A and Darweesh FF. Two-dimensional ultrasound and doppler in assessment of adnexal masses in correlation to histopathological analysis. Academic J Cancer Res 2014; 7(1):8-18.

4. Valentin L, Ameye L, Jurkovic D, Metzger U, Lécuru F, Van Huffel S, et al. Which extrauterine pelvic masses are difficult to correctly classify as benign or malignant on the basis of ultrasound findings and is there a way of making a correct diagnosis?. Ultrasound in Obstetrics and Gynecology: The Official Journal of the International Society of Ultrasound in Obstetrics and Gynecology 2006; 27(4):438-444.

5. Murthy NS, Shalini S, Suman G, Pruthvish S and Mathew A. Changing trends in incidence of ovarian cancer-the Indian scenario. Asian Pac J Cancer Prev 2009; 10(6):1025-1430.

6. Terzic MM, Dotlic J, Likic I, Ladjevic N, Brndusic N, Arsenovic N, et al. Current diagnostic approach to patients with adnexal masses: Which tools are relevant in routine praxis? Chin J Cancer Res 2013; 25:55-62.

7. Martin VR. Straight talk about ovarian cancer. Nursing 2005; 35(4):36-41.

8. Priya MHF, Vanusha and Kirubamani NH. Clinical correlation of ovarian mass with ultrasound findings and histopathology report. Int J Reprod Contracept Obstet Gynecol 2017; 6:5230-5234.

9. Sharadha SO, Sridevi TA, Renukadevi TK, Gowri R, Binayak D 
and Indra V. Ovarian masses: changing clinico histopathological trends. J Obstet Gynaecol India 2015; 65(1):34-38.

10. Jha R and Karki S. Histological pattern of ovarian tumors and their age distribution. Nepal Med Coll J 2008; 10(2):81-85.

11. Wasim T, Majrroh A and Siddiq S. Comparison of clinical presentation of benign and malignant ovarian tumours. J Pak Med Assoc 2009; 59(1):18-21.

12. Mondal SK, Banyopadhyay R, Nag DR, Roychowdhury S, Mondal PK and Sinha SK. Histologic pattern, bilaterality and clinical evaluation of 957 ovarian neoplasms: A 10 -year study in a tertiary hospital of eastern India. J Cancer Res Ther 2011; 7:433-437.

13. Topuz S, Saygili H, Akhan S, Yavuz E, Turfanda A and Berkman S. Differentiation of benign and malignant adnexal masses: Value of a morphologic scoring system. Eur J Gynaecol Oncol 2005;
26:209-212.

14. Pourissa M, Refahi $S$ and Moghangard F. The diagnostic accuracy of abdominal ultrasound imaging for detection of ovarian masses. Iran J Radiol 2007; 4(2).103-107.

15. Radhamani $S$ and Akhila MV. Evaluation of Adnexal MassesCorrelation of clinical, sonological and histopathological findings in adnexal masses. Int J Sci Stud 2017; 4(11):88-92.

16. Ashraf A, Shaikh AS, Ishfaq A, Akram A, Kamal F, Ahmad N, et al. The relative frequency and histopathological pattern of ovarian masses. J Biomed 2012; 28:98-102.

17. Makwana HH, Maru AM, Lakum NR, Agnihotri AS, Trivedi NJ and Joshi JR. The relative frequency and histopathological pattern of ovarian masses: 11-year study at tertiary care centre. Int J Med Sci Public Health 2014; 3:81-84.

\section{Authors Contribution:}

SKC- Concept and design of the study, manuscript preparation, reviewed the literature, critical revision of manuscript and review of the study; AS- Collected data and statistically analyzed and interpreted data and helped in preparing first draft of manuscript; SK- Literature search, statistically analyzed and interpreted data, prepared first draft of manuscript and critical revision of the manuscript; RP- Concept of study, collected data and review of study.

\section{Work attributed to:}

Department of Radiodiagnosis and Imaging, Manipal Teaching Hospital, Phulbari-11, Pokhara, Nepal.

Orcid ID:

Dr. Subash KC- (i) http://orcid.org/0000-0002-4819-7258

Dr. Ashish Shrestha- (1) http://orcid.org/0000-0001-8227-0896

Dr. Sagar Khadka- (D) http://orcid.org/0000-0002-1400-8498

Dr. Ramesh Poudel- (i) https://orcid.org/0000-0002-9938-0378

Source of Support: None, Conflict of Interest: None. 